\title{
Thermomechanical fatigue of grey cast iron brake discs for heavy vehicles
}

Gael Gigan, Viktor Norman, Johan Ahlström and Tore Vernersson

The self-archived postprint version of this journal article is available at Linköping University Institutional Repository (DiVA):

http://urn.kb.se/resolve?urn=urn:nbn:se:liu:diva-15.5587

N.B.: When citing this work, cite the original publication.

Gigan, G., Norman, V., Ahlström, J., Vernersson, T., (2019), Thermomechanical fatigue of grey cast iron brake discs for heavy vehicles, Proceedings of the Institution of mechanical engineers. Part $D$, journal of automobile engineering, 233(2), 453-467. https://doi.org/10.1177/0954407017739723

Original publication available at:

https://doi.org/10.1177/0954407017739723

Copyright: SAGE Publications (UK and US)

http://www.uk.sagepub.com/home.nav 


\title{
THERMOMECHANICAL FATIGUE OF GREY CAST IRON BRAKE DISCS FOR HEAVY VEHICLES
}

\author{
${ }^{1}$ Gaël Gigan, ${ }^{2}$ Viktor Norman, ${ }^{3}$ Johan Ahlström, ${ }^{1,4}$ Tore Vernersson \\ ${ }^{1}$ Chalmers University of Technology, Applied Mechanics, Gothenburg, Sweden \\ ${ }^{2}$ Linköping University, Management and Engineering, Linköping, Sweden \\ ${ }^{3}$ Chalmers University of Technology, Materials and Manufacturing Technology, Gothenburg, Sweden \\ ${ }^{4}$ ÅF Industry AB, Gothenburg, Sweden
}

KEYWORDS - disc braking, cast iron, fatigue life assessment models, laboratory experiments, thermomechanical fatigue

\begin{abstract}
The development of fatigue life assessment models for vehicle components exposed to thermomechanical fatigue supports the establishing of adequate maintenance intervals that neither cause unnecessary vehicle downtime, nor jeopardize the function of the components. In modern automotive applications, braking is closely related to safety and is commonly performed with disc brakes. Failure here may result in structural damage or even breakdown and loss of lives. In the present work, the cyclic response of grey cast iron is analysed and the fatigue life of brake discs made from this material is studied by use of four different fatigue life assessment models: the Smith-Watson-Topper model, the Coffin-Manson model, and two mechanism-based damage models. Results from isothermal and thermomechanical experiments on uniaxially loaded specimens are used for calibration of the models. Finally, the models are used to assess the life of a brake disc for a simulated brake dynamometer experiment. It is found that the fatigue model parameters that are calibrated using different sets of isothermal uniaxial test data show a substantial spread. A comparison with results from full-scale brake rig experiments shows that predictions by any of the models that have been calibrated using data from a well-designed thermomechanical test are in reasonable agreement with the estimated crack initiation phase for actual brake disc lives. It can be concluded that it is not sufficient to calibrate the studied fatigue life models using isothermal uniaxial tests for predictions of thermomechanical fatigue lives.
\end{abstract}

\section{INTRODUCTION}

\subsection{Background}

In heavy vehicles, brake discs are exposed to repeated thermomechanical load cycles due to consecutive braking and cooling. The frictional power generated between brake pads and brake disc causes an increase of the temperature at the friction surfaces resulting in a build-up of compressive stresses and wear. During cooling down, residual tensile stresses may arise, due to prior viscoplastic deformation at the friction surfaces, which promote cracking of the brake disc. For severe braking, cracks can develop after a relatively small number of cycles and this is often attributed to low-cycle fatigue. A reasonably accurate fatigue life prediction for mechanical components subjected to cyclic thermal and / or mechanical loading is critical for both maintenance and safety.

In heavy vehicle applications, brake discs are often made from grey cast iron. This material has good castability, involves a lower cost than steel or carbon ceramics and has a wide range of use owing to its favourable thermal properties. ${ }^{1}$ The microstructure of grey cast iron consists of graphite flakes within a ferrous matrix and is often characterized by size, distribution, shape and number of flakes. ${ }^{2,3}$ The graphite

\section{Corresponding author:}

Gaël Le Gigan, Department of Applied Mechanics, Chalmers University of Technology, Gothenburg SE-412 96, Sweden.

Email: gael.le-gigan@chalmers.se 
flakes will strongly affect the mechanical properties. ${ }^{4}$ The heterogeneous microstructure makes the material elastically non-linear and also reduces the tensile strength, mainly due to microcracks at the flakes. Due to these pre-existing cracks, it is commonly assumed, when studying cracking of grey cast iron, that initiation process could be disregarded and that only the propagation phase is of interest. ${ }^{5-7}$

The constitutive properties of materials exposed to cyclic plasticity are often modelled by the Chaboche model ${ }^{8,9}$ which can feature non-linear kinematic hardening, static recovery, dynamic recovery and rate-dependent behaviour. However, since grey cast iron materials exhibit an asymmetry in tension/compression, ${ }^{10}$ the material response cannot be captured by the traditional Chaboche model. Thus, a Gurson type material model is preferred. ${ }^{11}$ Here, the yield function is pressure-dependent, as in the Chaboche model, but it also includes a porosity variable that evolves with the inelastic strain and mean stress rate. This variable aims at mimicking the inclusion of spherical voids (intended to represent graphite flakes) in the material matrix. The use of such advanced material models still allows for numerical simulations in a reasonable amount of computational time.

\subsection{Literature}

Fatigue of a material is often associated with material dislocation, plastic deformation, ratchetting, corrosion and wear that may contribute to the initiation and, subsequently, the propagation of cracks. ${ }^{12}$ The fatigue life of the material may be associated with low cycle fatigue (LCF) or high cycle fatigue (HCF). Contrary to HCF, where an "infinite" or finite life may occur, LCF always leads to a finite number of cycles up to failure. Available models for fatigue life prediction vary in complexity and ease of assessing the required material parameters. Among them the Goodman, ${ }^{13}$ Morrow, ${ }^{14}$ Smith-WatsonTopper (SWT) ${ }^{15}$ Walker, ${ }^{16}$ Schütz, ${ }^{17}$ Gerber, ${ }^{18}$ Söderberg,,${ }^{19}$ Wellinger-Dietmann ${ }^{20}$ and Manson-CoffinBasquin ${ }^{21-23}$ models are frequently employed. The first four have been studied by Dowling et $\mathrm{al}^{24} \mathrm{where}$ SWT and Walker models show superior results. The Goodman, Morrow, SWT, Walker, Gerber and Söderberg models are generally used for cases of long fatigue lives, i e, high-cycle fatigue. ${ }^{25}$ The Walker and the SWT models are rather similar but the weighting between maximum stress and strain amplitudes differs between the models. ${ }^{25}$ The Schütz model uses a mean-stress sensitivity factor applicable to HCF and to various materials such as steel, ductile iron, malleable cast iron, grey cast iron and aluminium. ${ }^{26}$ When considering LCF, the positive (for compressive stresses) or negative (for tensile stresses) effects of the mean stress is absent or negligible due to the large amount of plastic deformation which annihilates this effect. ${ }^{27}$ The models listed above are far from the only ones as numerous other models have been derived from them. Morrow (and modified Morrow), SWT and Coffin-Manson-Basquin are considered to be the most commonly used fatigue models in engineering/industrial applications. Fash and Socie ${ }^{28}$ studied the fatigue behaviour and mean stress effects on grey cast iron by use of a simplified SWT fatigue life model considering only the product of maximum tensile stress and strain amplitudes.

Also, plastic strain energy density concepts can be used for fatigue life prediction. Materials developing high plastic strain energy density will result in components having a short life. Gocmez et $\mathrm{al}^{29}$ proposed a new fatigue life assessment model based on such an empirical approach. Some additional terms are proposed to account for induced damage at elevated temperatures, and verification up to $500{ }^{\circ} \mathrm{C}$ for isothermal LCF and $425{ }^{\circ} \mathrm{C}$ for thermomechanical fatigue (TMF) was carried out. The developed model is compared to SWT and Coffin-Mason fatigue life models. Good fatigue life predictions for ductile and vermicular cast irons are demonstrated. However, for grey cast iron, it is found that the Coffin-Manson model is the most suitable. Pevec et al ${ }^{30}$ studied isothermal low-cycle fatigue of a grey cast iron brake disc material and determined the parameters in the Coffin-Manson relation at room temperature, $500{ }^{\circ} \mathrm{C}, 600{ }^{\circ} \mathrm{C}$ and $700{ }^{\circ} \mathrm{C}$.

A different approach based on microgrowth of graphite flakes has been found useful for grey cast irons. Crack propagation is here commonly modelled by Paris' law. For classical crack growth analysis, Paris' 
law is only valid for uniaxial loading and for "long cracks", i e, no crack initiation. ${ }^{31-33}$ Moreover, Paris' law does not account for mean stress effects on crack growth as stated in its original form which was further improved to account for crack closure aspects. ${ }^{34}$ However, mechanism-based models for fatigue life prediction of cast irons under TMF loading have been found useful. ${ }^{35-38}$ Such models are based on an assumption that the crack propagation $(\mathrm{d} a)$ per cycle $(\mathrm{d} N)$ is proportional to the cyclic crack tip opening displacement $(\triangle C T O D)$ which is determined by the cyclic properties of the material.

\subsection{Aim of the present study}

Four fatigue approaches that could be used for estimation of the fatigue life of grey cast iron brake discs are studied and compared using results from both isothermal and TMF experiments but also fullscale brake rig experiments. The aim is to find a model that is suitable for assessment of fatigue of brake discs but also to establish the materials testing required for calibration of this model. In an application example, the models are used to assess the fatigue life of brake discs by use of results from simulations of full-scale brake rig experiments. Finally, the calculated fatigue lives are related to the results from the actual brake rig tests.

\section{LABORATORY FATIGUE EXPERIMENTS}

In the present work, results from three experimental studies are used. Detailed results on isothermal fatigue and TMF tests were reported by Skoglund et al. ${ }^{39}$ A short summary of these is given in the next section. Isothermal (non-fatigue) tests previously employed ${ }^{40}$ for material model calibration are discussed in Chapter 3.

\section{Isothermal fatigue testing}

Hour-glass shaped specimens ${ }^{40}$ having the diameter $7 \mathrm{~mm}$ were tested at the frequency $1 \mathrm{~Hz}$ with full reversal of the mechanical strain amplitudes $0.1 \%, 0.15 \%$ and $0.2 \%$ at $300{ }^{\circ} \mathrm{C}$ and $0.1 \%, 0.125 \%$ and $0.15 \%$ at $600{ }^{\circ} \mathrm{C}$. Four different brake disc materials were tested, see material D1 to D5 in the previous study. ${ }^{41}$ The effort of the present work concerns the most promising grey cast iron alloy brake disc material, denoted D4 where the chemical composition is shown in Table 1 with an ultimate tensile strength of about $150 \mathrm{MPa}$. The microstructure of the studied brake disc material D4 is displayed in Figure 1.

Mechanical degradation due to damage accumulation is depicted in Figure 2 for the test at mechanical strain amplitude $0.15 \%$ and $600{ }^{\circ} \mathrm{C}$, where two stress-strain cycles are given for the early life (cycles 10 and 50) and then at half-life, $75 \%, 85 \%$ and $95 \%$ towards complete specimen fracture (1 318 cycles). A decrease in the maximum tensile stress is observed after a period of increase during the early life. The compressive stress slightly increases during the early life before stabilizing and then decreases towards fracture. Figure 3 displays the stress-strain relationship at half-life for the two tested temperatures and all tested strain ranges. Due to non-linear elasticity and plasticity, an increase of strain leads to only moderate change in stress response.

Results for the isothermal fatigue tests are given in Table 2. The given lives have been assessed using a failure criterion, in accordance with TMF testing practice, ${ }^{42}$ defined as a $10 \%$ drop of stress range from a tangent line drawn at the last point of zero curvature in the plot of stress range versus number of cycles. The mechanical strain range $\Delta \varepsilon^{\mathrm{m}}$, inelastic strain range $\Delta \varepsilon^{\text {in }}$, stress range $\Delta \sigma$ and maximum stress $\sigma_{\max }$ are extracted at half-life. The number of cycles to failure $N_{\mathrm{f}}$ is also listed.

Table 1. Chemical composition of the studied grey cast iron material.

\begin{tabular}{lllllllllll}
\hline $\mathrm{C}$ & $\mathrm{Si}$ & $\mathrm{S}$ & $\mathrm{P}$ & $\mathrm{Mn}$ & $\mathrm{Cu}$ & $\mathrm{Ti}$ & $\mathrm{V}$ & $\mathrm{Nb}$ & $\mathrm{Mo}$ & $\mathrm{Cr}$ \\
\hline $4.00 \%$ & $1.20 \%$ & $0.06 \%$ & $0.02 \%$ & $0.45 \%$ & $0.50 \%$ & $0.01 \%$ & $0.10 \%$ & $0.10 \%$ & $0.00 \%$ & $0.11 \%$ \\
\hline
\end{tabular}




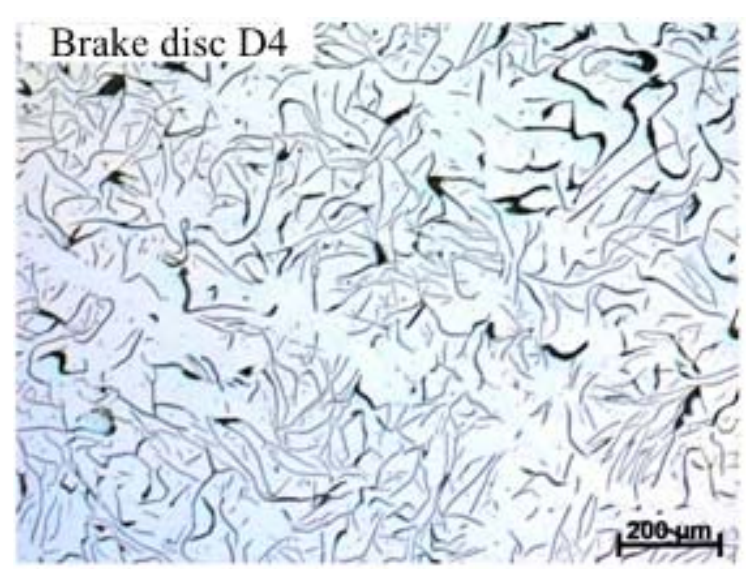

Figure 1. Microstructure of the studied brake disc material D4.

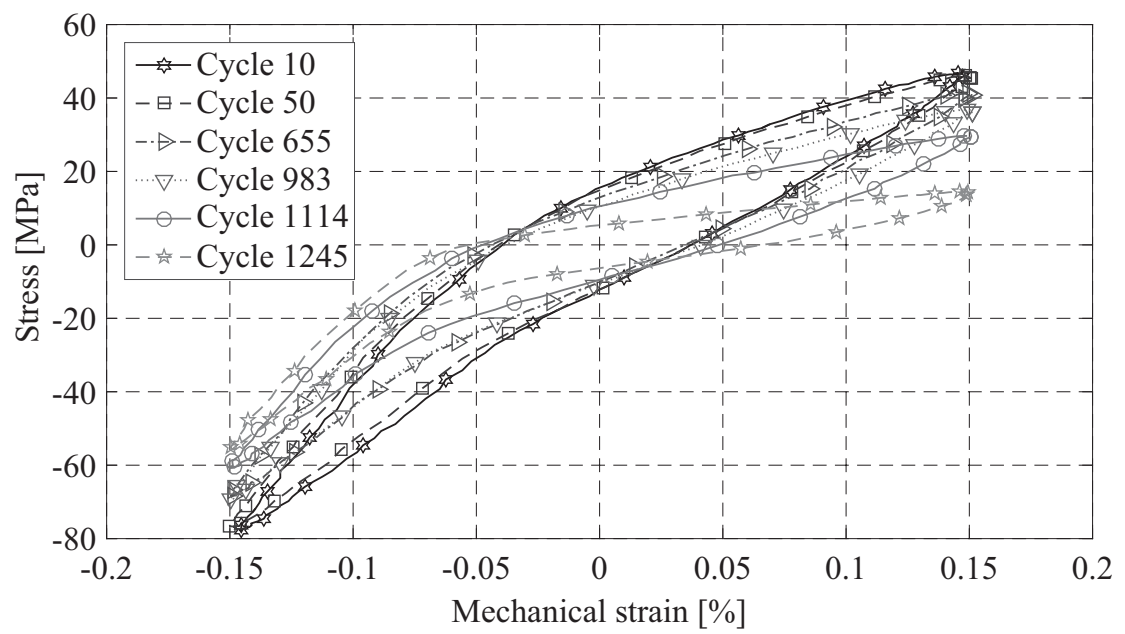

Figure 2. Stress-strain history for a selected number of cycles at $1 \mathrm{~Hz}$ cyclic loading and $0.15 \%$ mechanical strain amplitude at $600{ }^{\circ} \mathrm{C}$. Note that the total number of cycle to failure is 1318 .
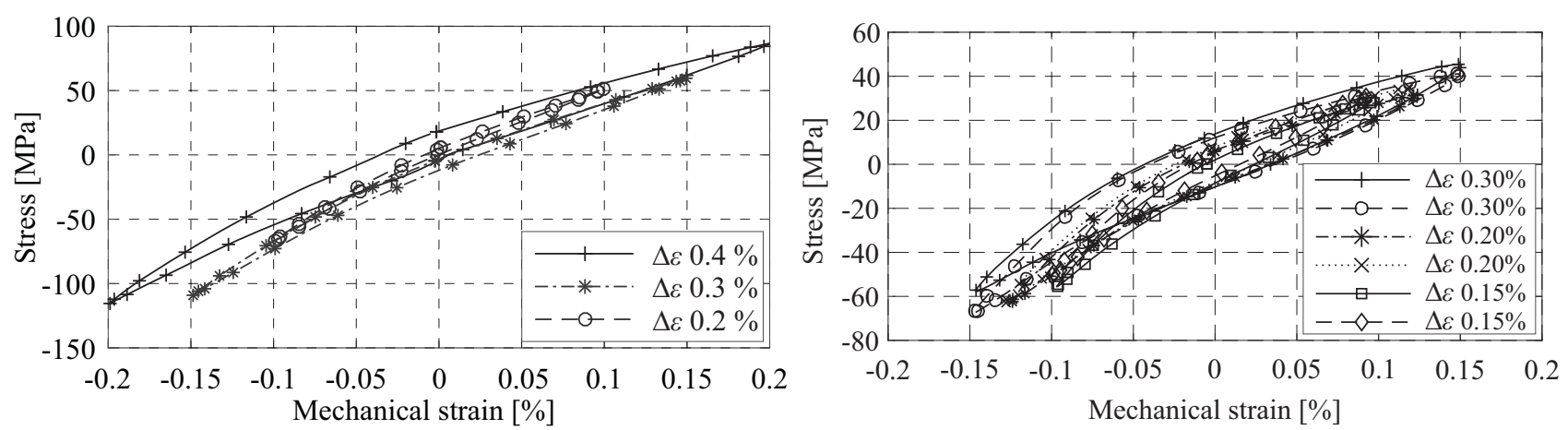

Figure 3. Stress-strain history at half-life at $300{ }^{\circ} \mathrm{C}$ (left) and $600{ }^{\circ} \mathrm{C}$ (right) for different strain ranges. Note the different axis scales in the two figures.

\section{Thermomechanical fatigue testing}

The TMF tests ${ }^{40}$ are cyclic out-of-phase uniaxial loading tests with compressive mechanical strains $-0.15 \%,-0.20 \%,-0.25 \%$ or $-0.30 \%$ for which the temperature is varying from $50{ }^{\circ} \mathrm{C}$ to $700{ }^{\circ} \mathrm{C}$. The specimen is compressed and heated via induction coils for $45 \mathrm{~s}$ and after this loaded in tension and cooled down for $255 \mathrm{~s}$. A dwell time of $30 \mathrm{~s}$ has been introduced at the highest compressive strains for some of the tests. The basic principle of out-of-phase thermomechanical loading is depicted in Figure 4 for the case of out-of-phase loading at full reversal, i e, strain ratio -1. It should be noted that, as in the present study, out-of-phase TMF is performed between 0 and compressive mechanical strain, i e, strain ratio -infinity. 
Table 2. Isothermal fatigue results for controlled cyclic strain tests at half-life.

\begin{tabular}{cccccc}
\cline { 2 - 6 } & $N_{\mathrm{f}}$ & $\Delta \varepsilon^{\mathrm{m}}[-]$ & $\Delta \varepsilon^{\text {in }}[-]$ & $\Delta \sigma[\mathrm{MPa}]$ & $\sigma \max [\mathrm{MPa}]$ \\
\hline $300{ }^{\circ} \mathrm{C}$ & 39200 & 0.20 & 0.0081 & 119 & 51.9 \\
& 10600 & 0.30 & 0.0179 & 170 & 59.9 \\
& 512 & 0.40 & 0.0450 & 205 & 86.0 \\
\hline $600{ }^{\circ} \mathrm{C}$ & 6100 & 0.20 & 0.0304 & 82.8 & 31.1 \\
& 9000 & 0.20 & 0.0334 & 73.0 & 32.9 \\
& 1400 & 0.25 & 0.0489 & 102 & 37.8 \\
& 2700 & 0.25 & 0.0526 & 100 & 35.9 \\
& 336 & 0.30 & 0.0820 & 105 & 45.4 \\
\hline
\end{tabular}

\section{ISOTHERMAL TESTING FOR EVALUATION OF CYCLIC PLASTICITY AND MATERIAL CALIBRATION}

Isothermal strain-controlled tests are presented and analysed in detail in the context of cyclic plasticity. Dedicated strain-controlled experiments inspired by Seifert and Riedel, ${ }^{35}$ especially designed for calibration of the material model, are carried out on the same type of specimens as for the thermomechanical fatigue tests. The tests have varying mechanical strain ranges and mechanical strain rates and also include periods of mechanical strain holding, see Figure 5. Each test ends with 100 cycles at the strain rate $10^{-3} \mathrm{~s}^{-1}$. The tests were performed at constant temperatures $20^{\circ} \mathrm{C}, 300{ }^{\circ} \mathrm{C}$, $400{ }^{\circ} \mathrm{C}, 500{ }^{\circ} \mathrm{C}, 600{ }^{\circ} \mathrm{C}$ and $650{ }^{\circ} \mathrm{C}$. Basic information regarding these tests were reported with the material model calibration, ${ }^{40}$ but an extended analysis is given in this study. The stress responses are shown in Figure 6 for the six temperature levels.
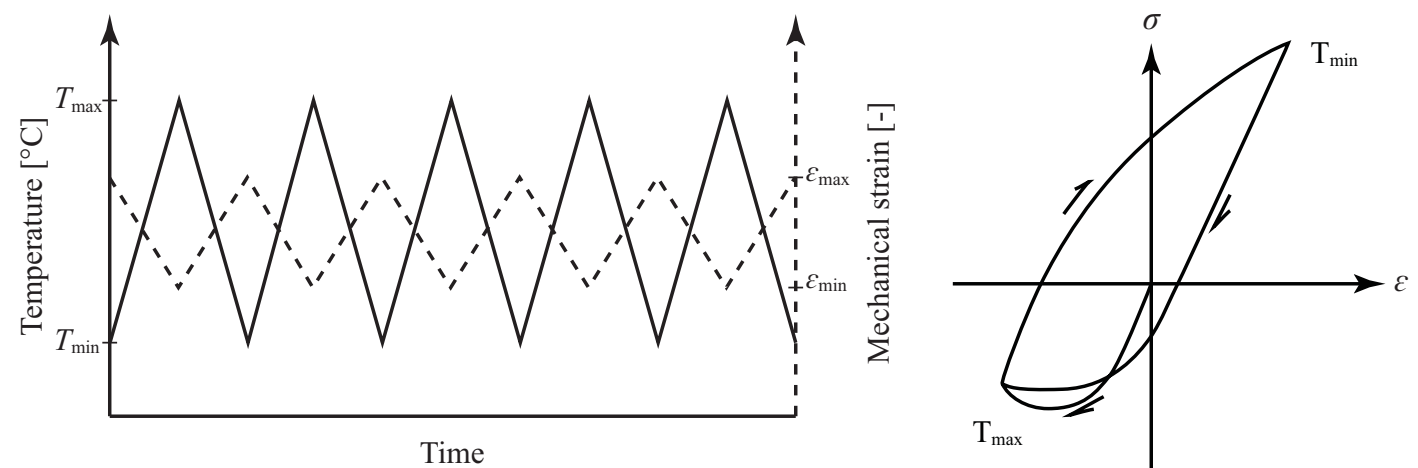

Figure 4. Principle of out-of-phase thermomechanical testing. During the tests, the temperature and the mechanical strain are controlled.

Table 3. Out-of-phase thermomechanical fatigue results for cyclic temperatures from 50 to $700{ }^{\circ} \mathrm{C}$.

\begin{tabular}{cccccc} 
& $N_{\mathrm{f}}$ & $\Delta \varepsilon^{\mathrm{m}}[-]$ & $\Delta \varepsilon^{\text {in }}[-]$ & $\Delta \sigma[\mathrm{MPa}]$ & $\sigma_{\max }[\mathrm{MPa}]$ \\
\hline \multirow{5}{*}{ No dwell } & 747 & 0.153 & 0.025 & 70 & 48 \\
& 339 & 0.202 & 0.031 & 85 & 58 \\
& 329 & 0.253 & 0.032 & 87 & 59 \\
\multirow{5}{*}{30 s dwell } & 157 & 0.304 & 0.077 & 92 & 58 \\
& 420 & 0.154 & 0.026 & 70 & 52 \\
& 304 & 0.204 & 0.036 & 73 & 54 \\
& 125 & 0.254 & 0.067 & 82 & 56 \\
& 57 & 0.304 & 0.096 & 107 & 81
\end{tabular}




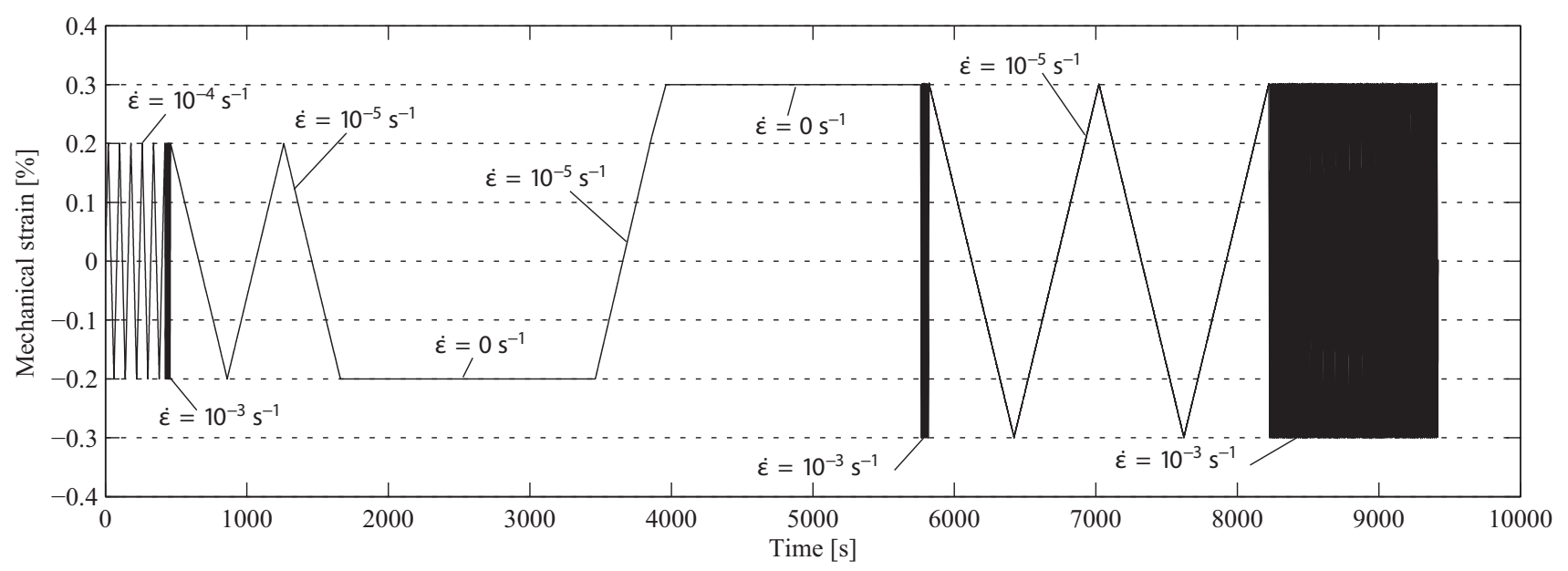

Figure 5. Isothermal strain cycles used for calibration of material model. The test comprises 120 cycles.

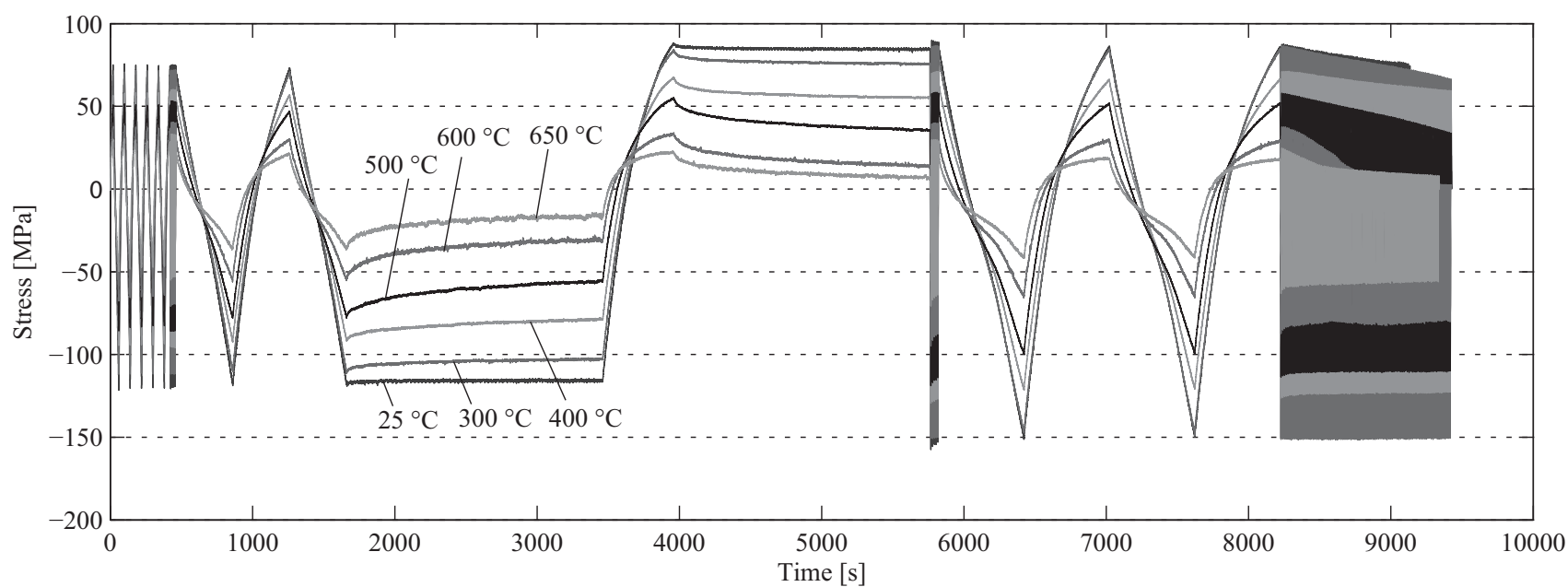

Figure 6. Stress responses from the isothermal calibration tests. Results are shown for 25, 300, 400, 500,600 and $650{ }^{\circ} \mathrm{C}$. Note that, here, the results are scaled down to compensate for observed variations between batches whereas the unscaled data are presenter later.

The mechanical behaviour of cast iron under cyclic loading exhibits both similarities and differences when compared to wrought steels. The properties of the matrix phase of cast iron can be expected to be similar to those of a steel with the same microstructure and composition. ${ }^{43}$ However, the graphite flakes introduce large discrepancies, the largest of which is the pronounced asymmetry between tensile and compressive loading due to the presence of cracks which were there from the start of the mechanical cycling. These cracks are formed by de-bonding or cracking of the graphite flakes. The hysteresis loop registered under strain-controlled cyclic loading, thereby gets a shape similar to that of a steel with large surface cracks, ${ }^{4,44}$ with the characteristic lower tensile peak stress and a knee in the stress-strain curve for compressive loading as the cracks close. For every flake cracking under tensional loading, the crack mouth opens and at a sufficiently high stress intensity, the crack tip blunts due to plastic deformation around the crack front. It has been shown that a high level of nominal compressive stress is needed for this plastic zone to sufficiently deform in compression to close the crack. ${ }^{45}$ Because of the large spread in local elastic and plastic strains, the elastic strain cannot easily be discerned from the total strain by analysis of the stress-strain loop shapes.

At the elevated temperatures studied here, the picture becomes further complicated, as viscous effects appear. Since creep mechanisms and creep rates are stress-dependent, the stress gradients near the cracks become important. Figure 5 shows the strain controlled test scheme, and Figure 6 the resulting true stress response. It is clear already from Figure 6 that the applied strain rate has a large influence on the flow stress and that there is an increase of the viscous behaviour with an increasing temperature 
as expected. During hold periods, stress relaxation occurs, more pronounced for the higher temperatures. A similar pattern repeats at the higher strain amplitude, until the peak stresses decay due to growth of larger cracks that would eventually have led to complete fracture.

Figure 7 shows the development of peak (left) and trough (right) stresses for the different test temperatures. One clear observation is that the peak stresses for all elevated temperatures decrease during the final 100 cycles run at constant strain rate $\left(\dot{\varepsilon}^{\mathrm{m}}=10^{-4} \mathrm{~s}^{-1}\right)$ and strain amplitude $\left(\Delta \varepsilon^{\mathrm{m}} / 2=0.30 \%\right)$, while the trough stresses remain at an almost constant level. The decay of peak stresses is probably due to growing cracks, and thus a decreased effective cross-sectional area. The successively lower stress levels with increasing test temperature display an effect of thermal softening, i e, easier dislocation motion due to increased thermal activation and crack growth, but at the highest temperatures, also in combination with microstructural degradation. At $0.20 \%$ mechanical strain amplitude, viscous effects on peak and trough stresses are visible by comparing the first 5 cycles run at $\dot{\varepsilon}^{\mathrm{m}}=10^{-4} \mathrm{~s}^{-1}$ with the following 5 cycles run at $\dot{\varepsilon}^{\mathrm{m}}=10^{-3} \mathrm{~s}^{-1}$ and an even stronger effect is seen for the slow cycles 11 and 12 run at $\dot{\varepsilon}^{\mathrm{m}}=10^{-5} \mathrm{~s}^{-1}$; naturally viscous effects become more pronounced at higher temperature. Similar effects are found for the higher mechanical strain amplitude $\Delta \varepsilon^{\mathrm{m}} / 2=0.30 \%$, when strain rate is varied. The tests at $600{ }^{\circ} \mathrm{C}$ and $650{ }^{\circ} \mathrm{C}$ show an anomalous inflection point of the peak stress starting between cycles 45 to 55 , which could be an effect of larger cracks forming. Some results at these two temperatures are much affected by this, see Figure 8 to Figure 10.

The development of the inelastic strain amplitude $\Delta \varepsilon^{\text {in }} / 2$ is illustrated in Figure 8 . It is determined as half the loop width at zero stress. As expected, the higher the temperature, the larger the inelastic strain amplitude.

Figure 9 shows the development of the tangent stiffness at unloading from peak stress. It was deduced by fitting a $2^{\text {nd }}$ degree polynomial to the unloading curve down to zero stress, and then examining the slope at peak strain. The decrease with cycle number resembles the decrease in peak stress, but up to $500{ }^{\circ} \mathrm{C}$ the influence of temperature is limited. At $600{ }^{\circ} \mathrm{C}$ and $650{ }^{\circ} \mathrm{C}$, the stiffness has decreased to half the original value already after some 50 cycles.

Irregularities seen in Figure 7 to Figure 10 at cycle 11 and 12 are induced by neighbouring holding periods that were disregarded in the present analysis whereas other discontinuities are due to either change in strain rate or strain range. Such hold periods make the following cycle start from a partially relaxed state. Uniaxial fatigue tests run at high strain amplitudes at 600 and $650{ }^{\circ} \mathrm{C}$ will, after rather few cycles, be affected by crack formation. Due to the fact that the tests were run under strain control condition, larger cracks do not immediately lead to failure; instead, tensile stresses during cycling diminish rapidly as the main crack grows. A carefully analysis of all hysteresis loops, to examine where the cracks are reaching sizes that affect global stresses, has been done. This means that the limitations of these results are known, and that it has been taken into account in the material model calibration.
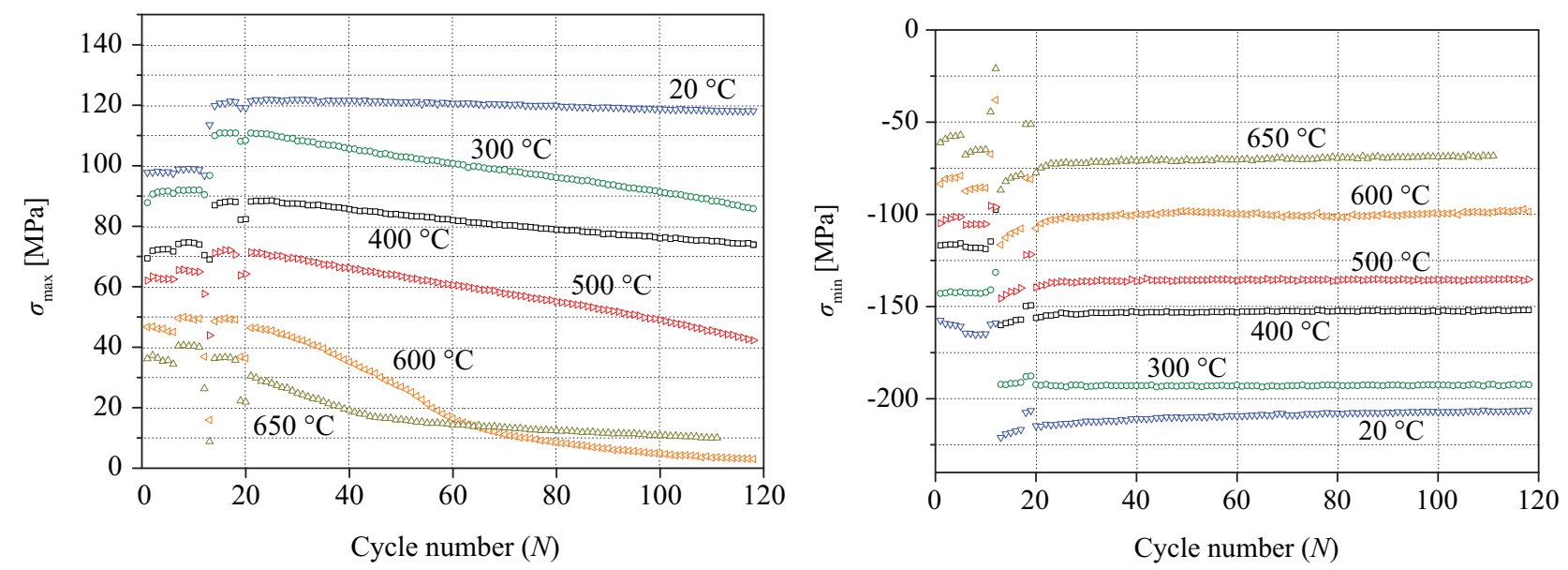

Figure 7. Development of peak (left) and trough (right) stresses. 

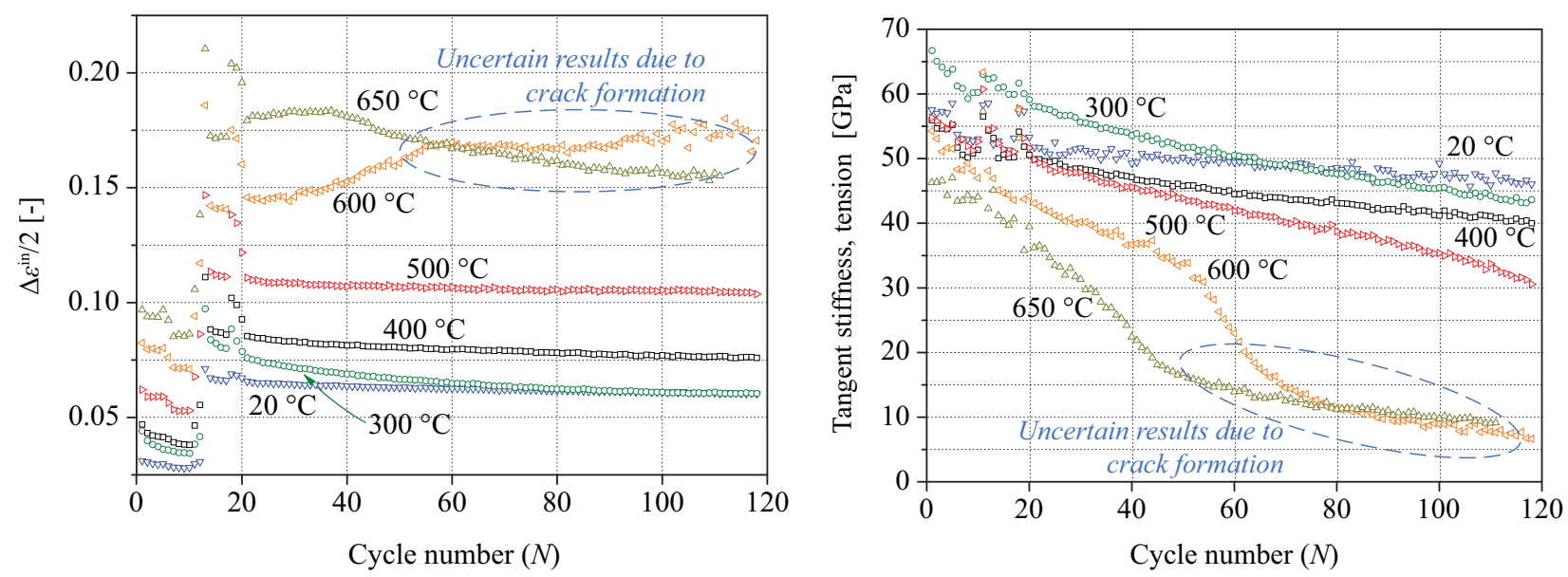

Figure 8. Development of inelastic strain amplitude. Figure 9. Tangent stiffness after peak load.

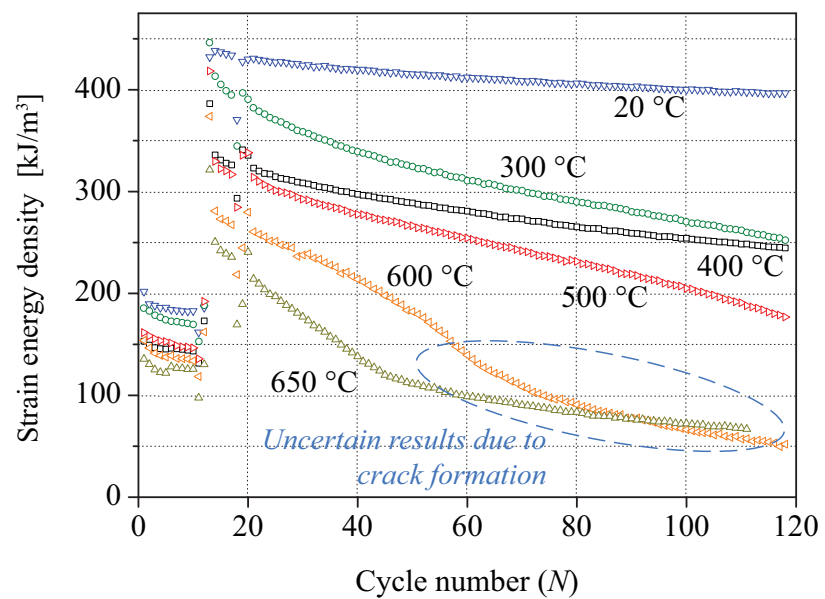

Figure 10. Strain energy density development. Plastic + tensile elastic work integrated for each cycle.

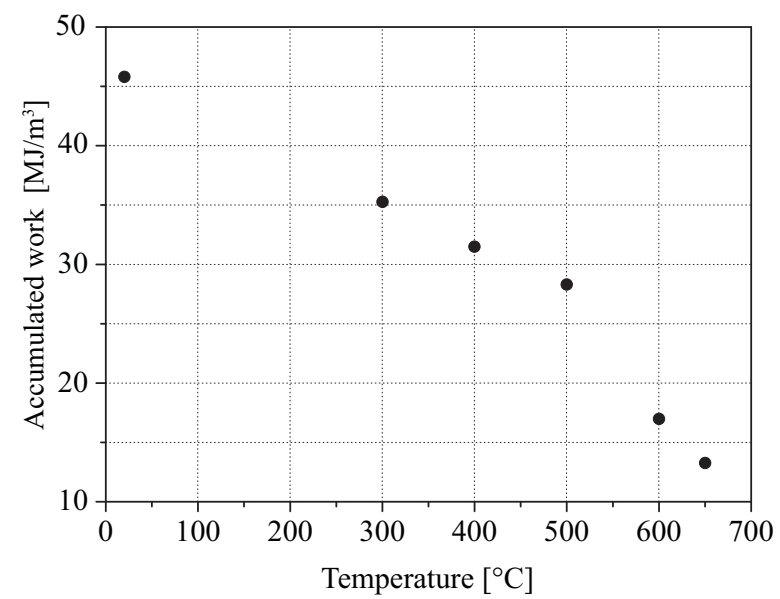

Figure 11. Accumulated work plastic + tensile elastic work during the entire life (120 cycles up to $600{ }^{\circ} \mathrm{C}$ and 113 cycles for test at $650{ }^{\circ} \mathrm{C}$ ).

The strain energy density, defined as the plastic work plus the tensile elastic work for each cycle ${ }^{46}$ was determined by integration of the loops. The strong influence of the strain amplitude is clearly seen from Figure 10 by comparing the first 12 cycles at strain amplitude $0.2 \%$ with the remaining ones at strain amplitude $0.3 \%$. If the contributions from all 120 cycles are summed, see Figure 11, it is found that the resulting accumulated energy decreases linearly with temperature up to $500{ }^{\circ} \mathrm{C}$. The accumulated work at the highest temperatures, $600^{\circ} \mathrm{C}$ and $650{ }^{\circ} \mathrm{C}$ lies below the extrapolation of this line, which could be expected since these tests had certain difficulties as described previously. Since the experimental base is limited, it will be difficult to base a fatigue life model on these data alone.

\section{FATIGUE LIFE MODELS AND CALIBRATION}

Three traditional fatigue models, which have previously been found useful ${ }^{29}$ also at elevated temperatures, are presented and calibrated using results from the isothermal tests and the thermomechanical tests. The fatigue life model based on Paris' law, which is intended for use at a given temperature range at the TMF test, is calibrated only using TMF data. 


\subsection{Fatigue life model based on microcrack propagation}

A fatigue life assessment model was developed by Norman et $\mathrm{al}^{47}$ for the compacted graphite iron ENGJV-400. It is based on assumptions related to an observation of fatigue microcrack initiation and propagation in compacted graphite irons at room temperature, ${ }^{48,49}$ during thermal cycling ${ }^{50}$ and thermomechanical fatigue. ${ }^{37,51}$ In particular, it is assumed that the average microcrack length attained in a representative element volume follows a Paris' law expression and that the end-of-life is associated with instantaneous crack coalescence occurring at a critical average microcrack length. More details about the model premises can be found in the references. ${ }^{47}$ Nonetheless, it is assumed that the model is applicable also to grey irons as supported by the close resemblance in the microstructure and fatigue cracking mechanisms of the two materials.

The mentioned fatigue life assessment model considers the specific case of combined thermomechanical and superimposed high-cycle fatigue (TMF-HCF), and is therefore slightly simplified here as the HCF contribution is non-existent. The model takes Paris' law for crack growth as the starting point,

$\frac{\mathrm{d} a}{\mathrm{~d} N}=C[\Delta K(\Delta \sigma, a)]^{n}$

Here $a$ is the average microcrack length, $N$ the number of cycles, $n$ a Paris' law exponent, $\Delta \sigma$ the stress range, $\Delta K$ the stress intensity factor range and $C$ a Paris' law coefficient. Under the above mentioned assumptions $^{47}$, Equation (1) can be simplified to constitute a fatigue damage law. Accordingly, the governing equation becomes

$D \int_{0}^{N_{\mathrm{f}}}\left[\sigma_{\max }(N)\right]^{n} \mathrm{~d} N=1$

where $\sigma_{\max }$ is the maximum engineering stress at each cycle, $N_{\mathrm{f}}$ is the number of cycles to failure and $D$ is a constant. The parameter $N$ and $D$ are seen in this approach as unknown constants which are to be determined by fitting to experimental data. The maximum stress $\sigma_{\max }$ can be taken from either experiments or a constitutive model. As reflected implicitly in Equation (1), the engineering stress at which the microcrack faces are closed, have been assumed to be zero throughout the whole life, in accordance with the experiments ${ }^{47}$ made on EN-GJV-400.

It is noted that Equation (2) is very similar to the Basquin relationship. ${ }^{52}$ If the maximum stress is approximated with a constant value, e g, the average maximum stress or the stress at mid-life, the integral in Equation (2) can be further simplified. Consequently, the number of cycles to failure and the average maximum stress then become related via a power law as

$\bar{\sigma}_{\max }=\left(N_{\mathrm{f}} D\right)^{-\frac{1}{n}}$

where $\bar{\sigma}_{\text {max }}$ denotes the average maximum stress, which here is taken as the maximum stress at halflife.

The numerical values of the Paris' law exponent $n$ and the constant $D$ are obtained by fitting Equation (2) to the TMF tests performed without hold time. The values of the parameters are presented in Table 4, see Section 4.5. The fatigue tests used to fit the parameters are compared to calculated values using Equations (2) and (3) and the parameters in Table 4, see Figure 12. It is important to note that the fitted parameters $D$ and $n$ are temperature-dependent and will therefore only correspond to this particular thermal cycle. 
The fatigue life is estimated by using curves $\sigma_{\max }(N)$ for both experimentally measured and simulated maximum stresses, where the parameters in Table 1 are employed for the latter. In the former case (experiments), equation (2) was employed. However, for the latter case (numerical simulation), only a few cycles were simulated and the fatigue lives were therefore calculated using equation (3), with the maximum stress taken as the average value. The outcome of the two cases is displayed in Figure 13. The scatter is increased when using the simulated stress response; however, most of the estimates are within $50 \%$ error margin.

It is noted that the TMF tests with $30 \mathrm{~s}$ hold time are also successfully described, see Figure 13, even though these data points were not included in the fitting procedure. It is concluded that there is no explicit additional microcrack propagation due to the addition of a hold time. Rather, the fatigue life reduction due to the hold time discussed in Section 2, is caused implicitly by the change in the maximum stress level when including hold times. However, it is observed that $N_{\mathrm{f}}$ of all TMF tests with

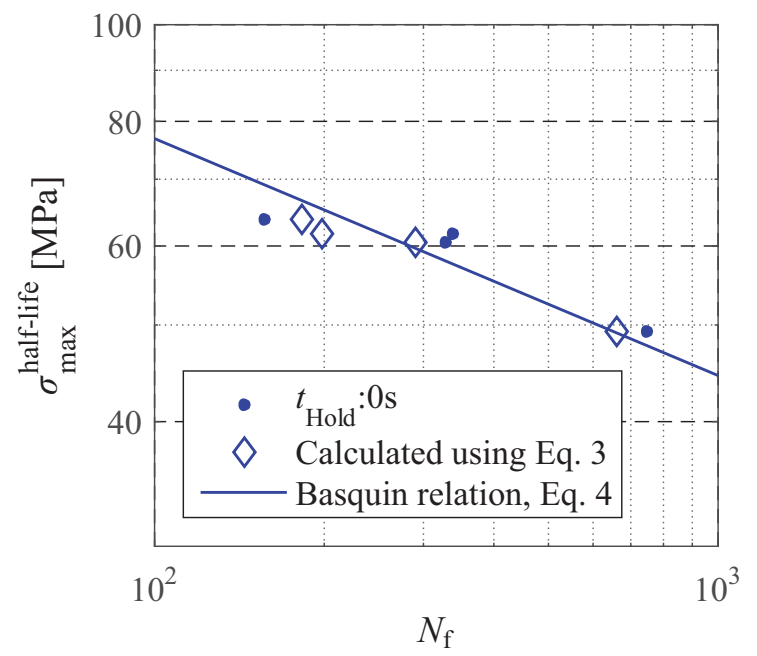

Figure 12. Maximum engineering stress at half-life as a function of the number of cycles to failure, $N_{\mathrm{f}}$, of TMF tests performed without hold time, compared to calculated values using Equations (2) and (3).
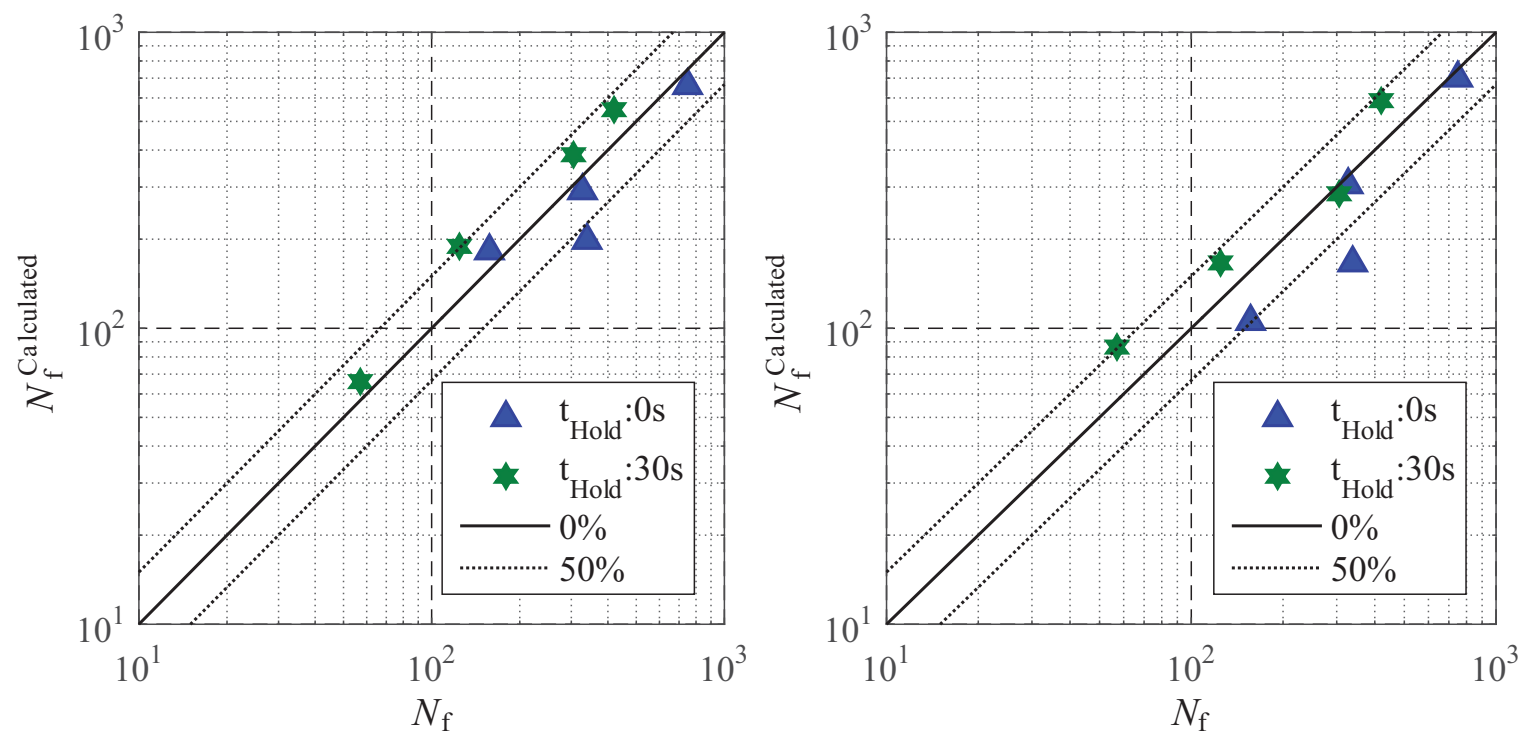

Figure 13. Comparison of experimental results and estimated number of cycles to failure when using maximum stress data from the TMF tests (left) and the constitutive model (right). 
$30 \mathrm{~s}$ of hold time tend to be overestimated, which suggests that fatigue life consumption might occur due to the hold times after all. Thus, lives predicted for tests with longer hold times might be overestimated by this model. It is noted that the constitutive numerical model includes negative mean stress while the microcrack model considers zero mean stress.

\subsection{Smith-Watson-Topper}

Fash $^{28}$ showed that a log-linear relationship between the Smith-Watson-Topper (SWT) parameter, which is half of the product between maximum stress $\sigma$ max and principal mechanical strain range $\Delta \varepsilon^{\mathrm{m}}$, and the fatigue life for grey iron specimens is suitable. It is expressed as

$\sigma_{\max } \frac{\Delta \varepsilon^{\mathrm{m}}}{2}=I_{\mathrm{SWT}}\left(N_{\mathrm{f}}\right)^{S_{\mathrm{SWT}}}$

with $I_{\mathrm{SwT}}=1.82$ and $S_{\mathrm{SwT}}=-0.25$ at room temperature for a grey cast iron material. ${ }^{28,49,53}$ This relationship avoids determination of elastic and plastic strains and provides the ability to include the mean stress effect. ${ }^{54}$

Calibration of the SWT model has been performed by use of the isothermal and thermomechanical fatigue experiments, see Figure 14. The parameters are given in Table 4 in Section 4.5. It is found that four completely different sets of $I_{\mathrm{SWT}}$ and $S_{\mathrm{SWT}}$ are produced when fitted using the different sets of data. It can be noted that the ability to predict fatigue life within each group is successful with rather small scatter. Moreover, the slopes of the curves for the isothermal tests in the diagram are consistent, and also consistent with the slope given in the literature. ${ }^{28}$ However, the fatigue life calculated using parameters for $300{ }^{\circ} \mathrm{C}$ will overestimate the fatigue life at $600{ }^{\circ} \mathrm{C}$ by a factor of about 20 . For the studied grey cast iron material and available test results, it is found that isothermally calibrated models will in general not be able to predict fatigue life in a TMF setting. What is more important is that the fatigue life predictions based on isothermal calibration will overestimate the actual fatigue life, making them non-conservative which is not acceptable when employed for brake disc design. It should be noted here that the isothermal tests are performed at $300^{\circ} \mathrm{C}$ and $600{ }^{\circ} \mathrm{C}$, while the TMF tests go from $50{ }^{\circ} \mathrm{C}$ to $700^{\circ} \mathrm{C}$.

\subsection{Coffin-Manson}

For the tests on grey cast iron studied here, the plastic deformation is significant and the lives are generally short. Thus, low-cycle fatigue is dominating and the Coffin-Manson relation gives

$\frac{\Delta \varepsilon^{\mathrm{in}}}{2}=\varepsilon_{\mathrm{f}}^{\prime}\left(2 N_{\mathrm{f}}\right)^{c}$

where $\varepsilon_{\mathrm{f}}^{\prime}$ is the ductility coefficient.

Calibration of the Coffin-Manson model has been performed using the isothermal and thermomechanical fatigue experiments, see Figure 15. The parameters are given in Table 4 in Section 4.5. Again four completely different sets of model parameters are found when fitting using the four different sets of data individually. It can be noted that the ability to predict fatigue life within each group is successful with rather small scatter. The fatigue life calculated using parameters for $300{ }^{\circ} \mathrm{C}$ will underestimate the fatigue life at $600{ }^{\circ} \mathrm{C}$ by a factor of less than 10 for the plastic strains assessed here. For the studied grey cast iron material and available test results, it is found that it will generally not be successful for isothermally calibrated models to predict fatigue life using a TMF setting. The fatigue life predictions will generally overestimate the actual life and, thus again, make them nonconservative. However, the estimates at short lives (less than some hundred cycles) from the $300{ }^{\circ} \mathrm{C}$ fitting are not very far from the TMF lives. It should be noted here again that the TMF tests go from $50{ }^{\circ} \mathrm{C}$ to $700{ }^{\circ} \mathrm{C}$. 


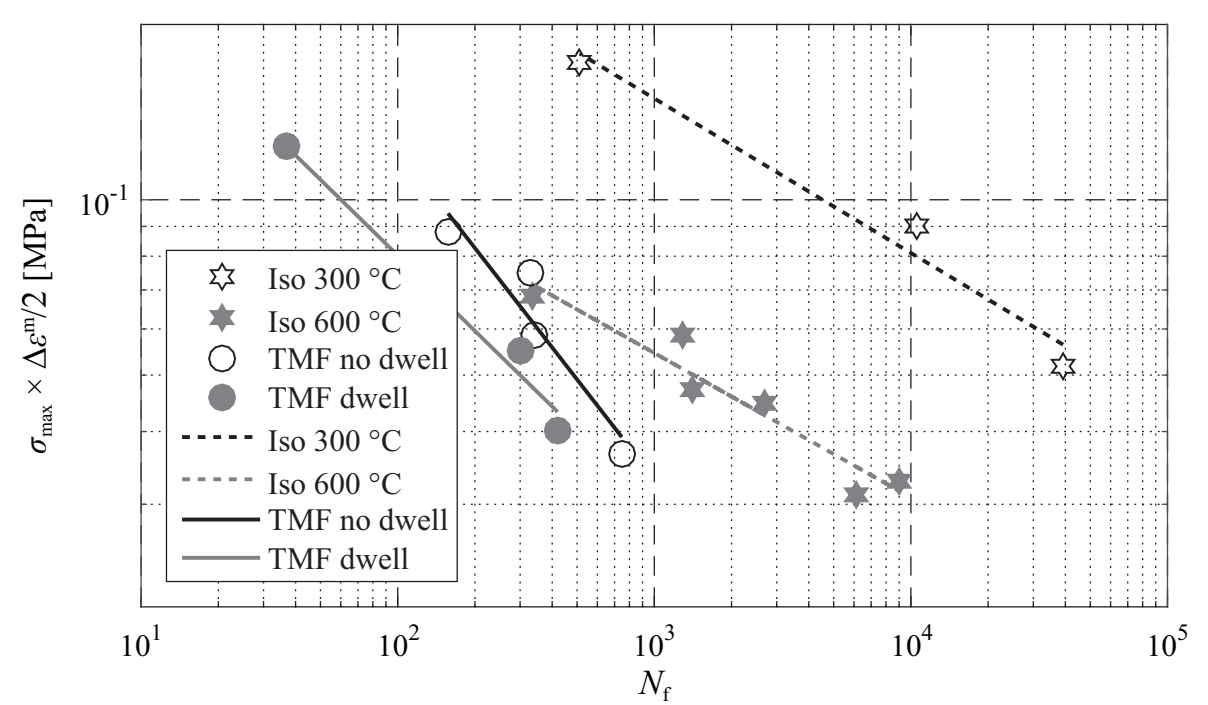

Figure 14. Calibration of the SWT model with damage parameter $\sigma_{\max } \times \Delta \varepsilon^{\mathrm{m}} / 2$ for the four sets of experimental data. Lines show lives for the fitted models. Note that TMF tests go from $50{ }^{\circ} \mathrm{C}$ to $700{ }^{\circ} \mathrm{C}$.

\subsection{Mechanism based $D_{\text {TMF-model }}$}

In a recent work, Seifert ${ }^{35}$ and Metzger $^{37}$ proposed a fatigue life model for combined isothermal $\mathrm{LCF} / \mathrm{HCF}$ and thermomechanical HCF loading. The crack growth law for this model, here denoted the "DTMF-model", is expressed as

$\frac{\mathrm{d} a}{\mathrm{~d} N}=\beta d_{n^{\prime}} D_{\mathrm{TMF}} a$

where $a$ is the crack length, $\beta$ is a factor depending on the volume fraction of the graphite inclusion and other microstructural aspects relative to the graphite morphology (size, shape), and $d_{n \prime}$ is a hardening-dependent factor that can be fitted by a third-order polynomial and is a function of the Ramberg-Osgood exponent. ${ }^{55}$ The Ramberg-Osgood equation relates the strain to the stress in a nonlinear manner by decomposing the strain into one elastic and one plastic part. The hardening behaviour of the material is accounted for by a so-called cyclic strain hardening parameter denoted $n^{\prime}$. The damage parameter $D_{\mathrm{TMF}}$ is expressed as

$D_{\mathrm{TMF}}=\frac{Z_{D}}{\sigma_{\mathrm{cy}}} F(t, \boldsymbol{\sigma}, \theta)$

where $F(t, \sigma, \theta)$ is a function of time history, stress and temperature. However, for cast irons $F=1$ is used. ${ }^{35}$ The cyclic yield stress $\sigma_{\text {cy }}$ is defined by the $0.2 \%$ offset with respect to the point of load reversal. For thermomechanical loadings, $D_{\mathrm{TMF}}$ is the average value computed for rising and falling temperatures. The parameter $Z_{\mathrm{D}}$ is based on elastic-plastic fracture mechanics and found as

$Z_{\mathrm{D}}=1.45 \frac{\left(\Delta \sigma_{\mathrm{eff}}\right)^{2}}{E}+2.5 \frac{\Delta \sigma \Delta \varepsilon^{\mathrm{p}}}{\sqrt{1+3 n^{\prime}}}$

with

$\Delta \sigma_{\mathrm{eff}}=\frac{3.72}{\left(3-R_{\sigma}\right)^{1.74}} \Delta \sigma, R_{\sigma}=\frac{\sigma_{\min }}{\sigma_{\max }}$ and $\Delta \sigma=\left|\sigma_{\max }-\sigma_{\min }\right|$ 


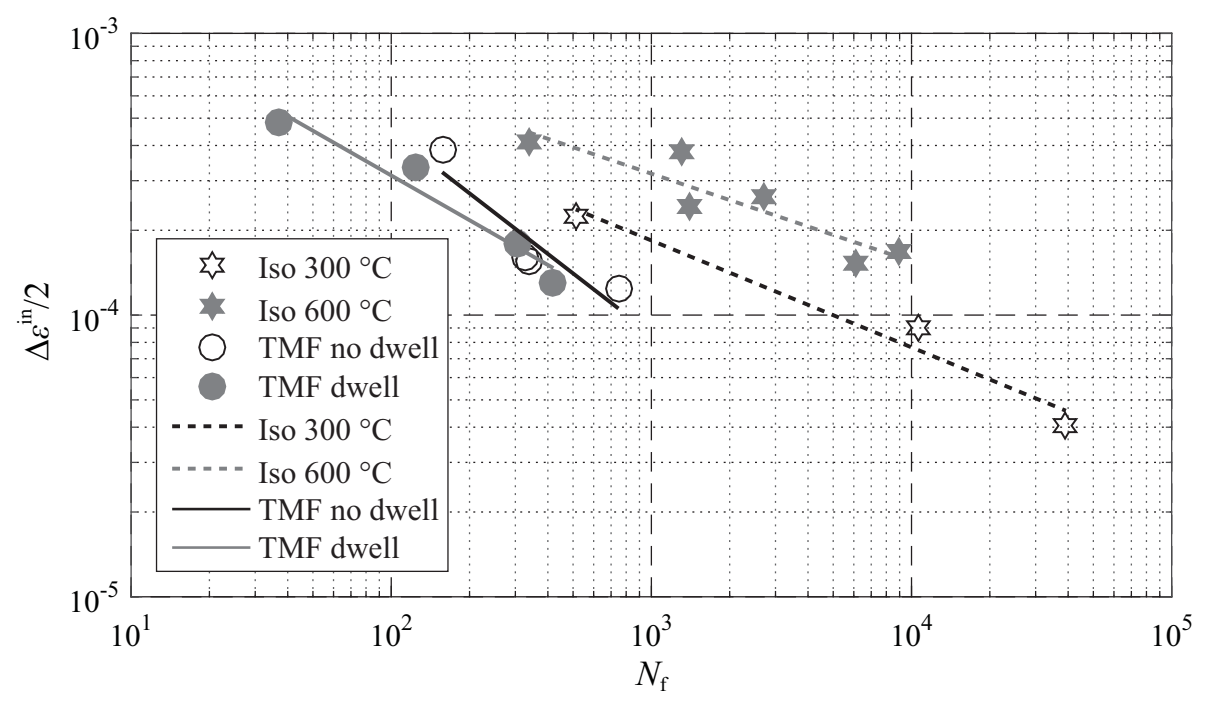

Figure 15. Calibration of Coffin-Manson model with damage parameter $\Delta \varepsilon^{\text {in }} / 2$ for the four sets of experimental data. Lines show lives for the fitted models. Note that TMF tests go from $50{ }^{\circ} \mathrm{C}$ to $700{ }^{\circ} \mathrm{C}$.

Young's modulus $E$ is taken as the arithmetic average at reversal for a given cycle. To this end, a fatigue life model is proposed, where $A$ and $B$ are parameters to be fitted to experiments, as ${ }^{35}$

$N_{\mathrm{f}}=A\left(D_{\mathrm{TMF}}\right)^{-B}$

Calibration of the $D$ TMF-model has been performed using the isothermal and thermomechanical fatigue experiments, see Figure 16. The parameters are given in Table 4 in Section 4.5. It is found that the relationships for $300{ }^{\circ} \mathrm{C}$ and $600{ }^{\circ} \mathrm{C}$ almost coincide in the fitting of different sets of data and that the scatter is rather small. However, it is also found that it will not be particularly successful to predict fatigue life using the isothermally calibrated models in the TMF setting. The life predictions will overestimate the actual life by a factor of about 10 for long lives (1000 TMF cycles), but maybe only by a factor 2 for short lives ( 100 cycles). It can also be noted that the method makes the experimental results from the TMF testing with and without hold time to almost fall on one line.

\subsection{Summary of fatigue models}

The parameters for the four studied models are summarized in Table 4. The parameters vary significantly between the sets of experimental data. Comparing the SWT parameters obtained in the present study to those given by Fash and Socie $\left(I_{\mathrm{SWT}}=1.82\right.$ and $\left.S_{\mathrm{SWT}}=-0.25\right){ }^{28}$ one can see that the two isothermal tests at $300{ }^{\circ} \mathrm{C}$ and $600{ }^{\circ} \mathrm{C}$ give approximately the same exponent $S$ swt, but a lower value of $I_{\mathrm{SWT}}$, which is found to decrease with temperature. It can be noted that the material studied here has an ultimate tensile strength at room temperature of about $150 \mathrm{MPa}$ whereas the material studied by Fash and Socie ${ }^{28}$ had $228 \mathrm{MPa}$. The detailed study in Section 3 shows that the material behaves quite similarly at room temperature and $300{ }^{\circ} \mathrm{C}$. The calibrations to TMF tests performed here with temperatures up to $700{ }^{\circ} \mathrm{C}$ show differing $S_{\text {SwT }}$ and $I_{\text {swt }}$ parameters. 


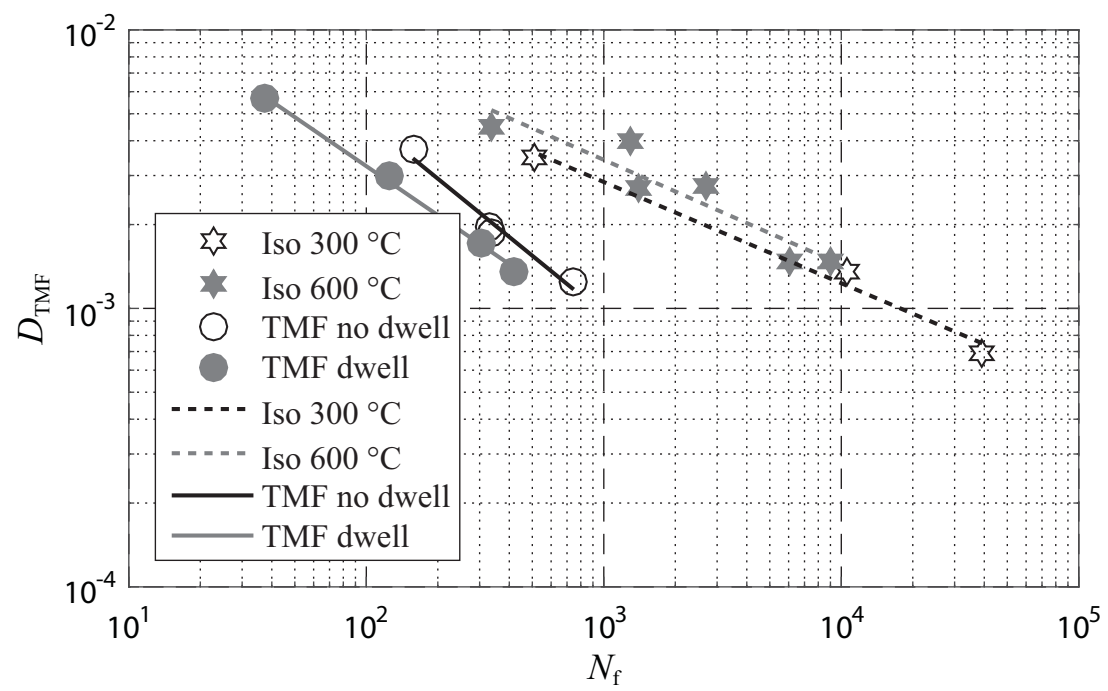

Figure 16. Calibration of D-TMF model with damage parameter $D_{\text {TMF }}$ for the four sets of experimental data. Lines show lives for the fitted models. Note that TMF tests go from $50{ }^{\circ} \mathrm{C}$ to $700{ }^{\circ} \mathrm{C}$.

Table 4. Parameters for fatigue models obtained by fitting using both isothermal and TMF data. Note that $I_{\text {SWT }}$ is in $\mathrm{MPa}$ and that $D$ is in $(\mathrm{MPa})^{-\mathrm{n}}$. The remaining parameters are non-dimensional. Note that TMF tests go from $50{ }^{\circ} \mathrm{C}$ to $700{ }^{\circ} \mathrm{C}$.

\begin{tabular}{|c|c|c|c|c|c|c|c|c|}
\hline & \multicolumn{2}{|c|}{ SWT } & \multicolumn{2}{|c|}{ Coffin-Manson } & \multicolumn{2}{|c|}{$D_{\text {TMF }}$} & \multicolumn{2}{|c|}{$\begin{array}{c}\text { Microcrack } \\
\text { model }\end{array}$} \\
\hline & $I_{\mathrm{SWT}}$ & $S_{\text {SWT }}$ & $\varepsilon_{\mathrm{f}}^{\prime}$ & $c$ & $A$ & $B$ & $n$ & $D$ \\
\hline $300^{\circ} \mathrm{C}$ & 0.933 & -0.265 & $2.527 \mathrm{E}-2$ & -0.379 & 8.867 & 1 & - & - \\
\hline $600{ }^{\circ} \mathrm{C}$ & 0.303 & -0.248 & $2.727 \mathrm{E}-2$ & -0.311 & 5.453 & 1 & - & - \\
\hline TMF no dwell & 1.667 & -0.567 & $1.189 \mathrm{E}-2$ & -0.714 & 0.686 & 1 & 4.200 & $1.150 \mathrm{E}-10$ \\
\hline TMF with dwell & 0.585 & -0.431 & $3.553 \mathrm{E}-2$ & -0.527 & 0.390 & 1 & - & - \\
\hline
\end{tabular}

Grey cast iron was also studied by Gocmez et $\mathrm{al}^{29}$ (ultimate tensile strength $250 \mathrm{MPa}$ ) and Pevec et al ${ }^{30}$ (ultimate tensile strength $284 \mathrm{MPa}$ ). Due to the lower strength of the material studied here, a straightforward comparison is difficult. Gocmez et $\mathrm{al}^{29}$ found parameters for SWT (ISWT $=1.82$ and $\left.S_{\mathrm{SWT}}=-0.296\right)$ to be very similar to those of Fash and $\operatorname{Socie}^{28}\left(I_{\mathrm{SWT}}=1.82\right.$ and $S_{\mathrm{SWT}}=-0.25$ at room temperature). In that study, Gocmez et al ${ }^{29}$ calibrated to TMF and isothermal experiments from $20{ }^{\circ} \mathrm{C}$ up to $450{ }^{\circ} \mathrm{C}$ to find a single relationship for Coffin-Manson, SWT and D-TMF models. In Pevec et al ${ }^{30}$ Coffin-Manson parameters were calibrated individually to isothermal tests at $20^{\circ} \mathrm{C}, 500{ }^{\circ} \mathrm{C}, 600{ }^{\circ} \mathrm{C}$ and $700{ }^{\circ} \mathrm{C}$. As in the present study, the parameters differed substantially between temperatures. The DTMF model has previously been verified for use up to $425{ }^{\circ} \mathrm{C}$ for both isothermal and TMF tests. In the present work, considering temperatures up to $700{ }^{\circ} \mathrm{C}$, the damage parameter $D_{\mathrm{TMF}}$ has been found to vary significantly between the isothermal tests and the TMF tests. As stated earlier, the parameters in the microcrack model cannot be compared with previous work such as Norman et al, ${ }^{56}$ as they are specific to a given temperature cycle and material.

\section{MODELLING OF DISC BRAKING}

The fatigue life assessment models will be applied to an example of disc braking, with thermal loading corresponding to the presence of hot bands on the friction surfaces during three identical braking cycles. Calculated lives are compared and discussed. Numerical simulations of the "reference" brake 
disc have been presented in the previous work. ${ }^{57}$ The disc life is here assessed based on the models described above and is compared to the results from full-scale brake rig experiments. ${ }^{41}$

\subsection{FE model}

In the following, a brake disc of hat type with 36 straight vanes is assessed, which has previously been studied in full-scale brake dynamometer experiments ${ }^{41}$ and by numerical simulation ${ }^{57}$ using a dedicated and calibrated material routine. ${ }^{40}$ The model exploits symmetry conditions and a $5^{\circ}$ sector is used, see Figure 17 (left).

\subsection{Loading}

As for the brake dynamometer experiments, ${ }^{41}$ each brake cycle has a duration of $45 \mathrm{~s}$, a constant torque of $2.8 \mathrm{kNm}$ and a rotational speed of $425 \mathrm{rpm}$ (power $125 \mathrm{~kW}$, vehicle speed $80 \mathrm{~km} / \mathrm{h}$ ), followed by cooling to $50{ }^{\circ} \mathrm{C}$. Temperature patterns have been identified and reproduced ${ }^{57} \mathrm{~A}$ thermal loading observed in the full-scale experiments is introduced as a prescribed heat flux distribution in a dedicated user subroutine in the FE code Abaqus, see Figure 17 (right). It consists of one hot band on the hat side and two hot bands on the piston side.

\subsection{Material model}

The constitutive relationship based on a modified Gurson-Tvergaard-Needleman (GTN) model calibrated for the present brake disc material in a previous work ${ }^{40}$ is employed. It is implemented in a Fortran user subroutine (UMAT) for use with the FE code Abaqus. The material routine features nonlinear elasticity, plasticity with kinematic hardening, viscoplasticity and asymmetry in tension and compression of the yield strength. The model has a total of 32 material parameters (of which 18 are temperature-dependent) and calibration was performed for temperatures between room temperature and $650{ }^{\circ} \mathrm{C}$. Validation was achieved using out-of-phase thermomechanical experiments with uniaxial mechanical strain from 0 to $-0.3 \%$ and temperatures from $50{ }^{\circ} \mathrm{C}$ to $700{ }^{\circ} \mathrm{C}$. The material parameters were extrapolated up to $700{ }^{\circ} \mathrm{C}$.

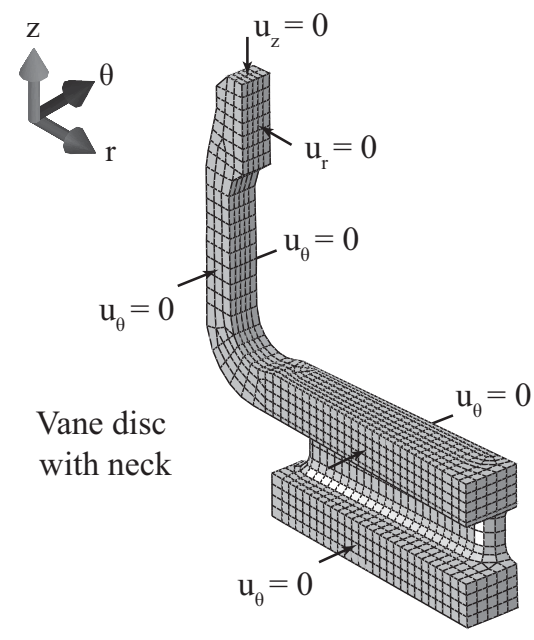

a)

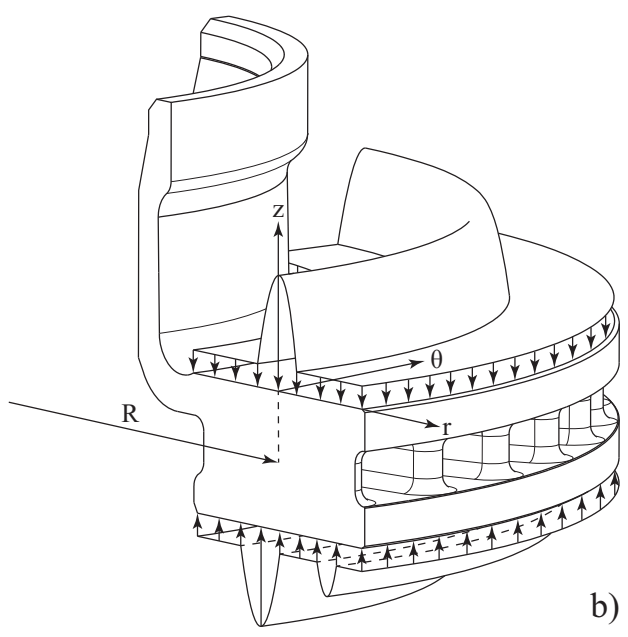

Figure 17. FE mesh for vane disc with neck together with mechanical boundary conditions and thermal loading with one hot band on the hat side (maximum intensity $1.15 \mathrm{MW} / \mathrm{m}^{2}$ ) and two hot bands on the piston side (maximum intensities $0.70 \mathrm{MW} / \mathrm{m}^{2}$ and $0.61 \mathrm{MW} / \mathrm{m}^{2}$ ). 


\subsection{Finite element results}

For the loading case studied here, the brake disc reaches about $670{ }^{\circ} \mathrm{C}$ at the middle of the hot band on the hat side, see Figure 18 (left). Disc cracking has previously been found to be related to the band and for this reason, results useful for assessing of the fatigue models are extracted for the centre of the band, see Figure 18 (right). The TMF tests reported earlier were aimed at reproducing the strain and temperature variations at braking. However, the mechanical strain applied to the specimens has the maximum range of $0.3 \%$ whereas the calculated mechanical strain range in the simulated full-scale brake rig experiment is about $0.5 \%$.

\subsection{Assessment of disc life}

The predictions of the four fatigue life assessment models applied to the FE model results for the brake disc are given in Table 5. The life of the tested brake discs in the previous experimental work was 800 and 1000 cycles and related to global cracking of the brake disc. ${ }^{41}$ It should be noted that the failure criterion used in that study corresponded to when a crack of length $80 \mathrm{~mm}$ was observed on the friction surfaces. The crack length on the friction surface was first measured at 100 cycles and was then about $15-20 \mathrm{~mm}$. After this point, the remaining fatigue life was governed by macroscopic crack propagation.

The fatigue life assessment models studied here are calibrated to tests where failure is defined as a given decrease in load carrying capacity of the specimen, which for the cast iron could indicate a crack size of, say, a few millimetres in the cylindrical test specimens. This is associated with the coalescence of microstructurally small cracks and the appearance of a macroscopic crack, a phenomenon which may be called "fatigue crack initiation" in a classical fatigue context. For the brake disc, the predicted fatigue life could then similarly be explained by the linking up of microcracks in order to form macroscopic cracks, having lengths of, say, a few millimetres. ${ }^{25}$ This would then, roughly speaking, correspond to some 10 braking cycles, in order to reach a $1 \mathrm{~mm}$ crack length, after which macroscopic crack growth takes place. Assuming a linear growth of the crack for the first 100 braking cycles, it would lead to a $10 \mathrm{~cm}$ crack length. This is in line with the experiment as the initial growth of the crack is quicker than around the middle of its life.

The calibration using TMF without dwell periods shows a rather good agreement between models and also with the full-scale tests. This could perhaps be attributed to the rather similar temperature-strain cycling at TMF specimen testing and at full-scale experiments. The microcrack model predicts the shortest life; 10 cycles to failure and the other models between 18 and 44 cycles.

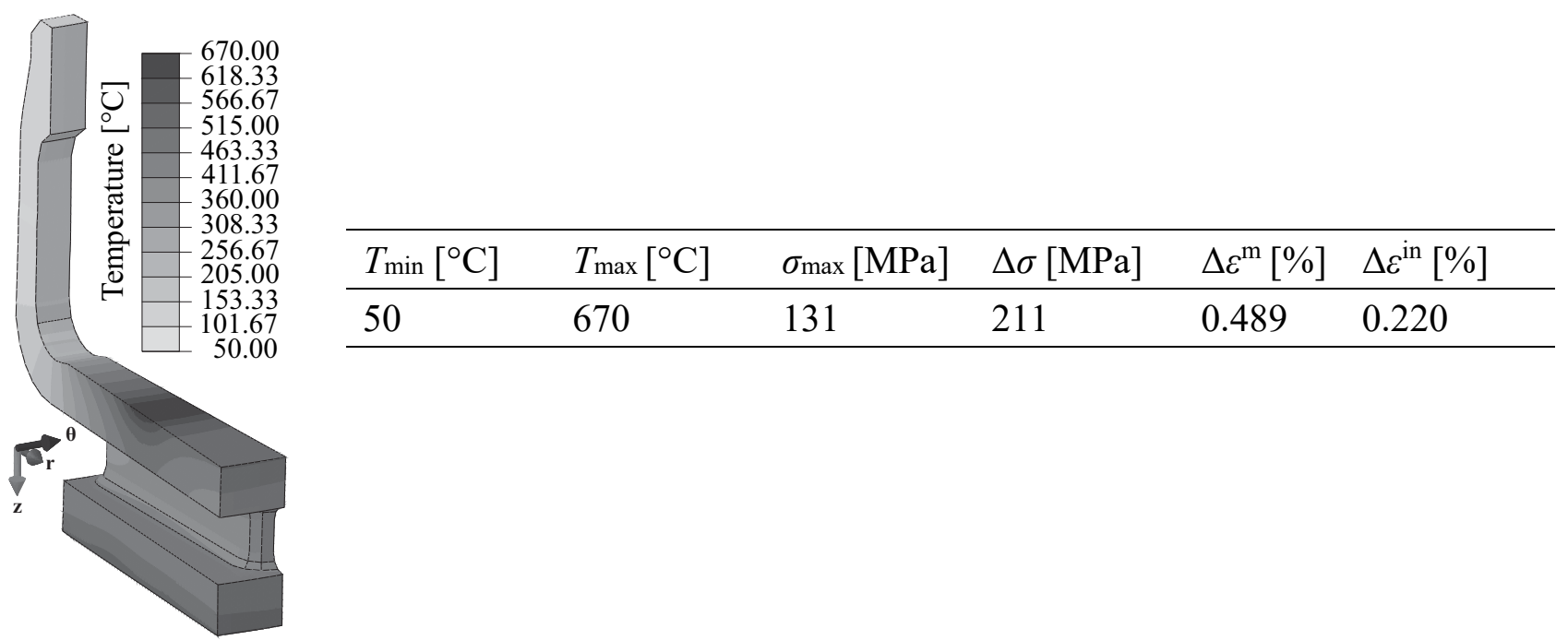

Figure 18. Main characteristics of the simulated brake cycle. Temperature at end of $45 \mathrm{~s}$ braking (left) and table of data extracted for the last cycle (right). On the hat side surface mid-radius of the vane. 
Table 5. Predicted life $N_{\mathrm{f}}$ of the simulated brake disc taking the last cycle as stabilized. Data are computed using the four models.

\begin{tabular}{lllll}
\hline Calibration & SWT & Coffin-Manson & $D_{\text {TMF }}$ & Microcrack model \\
\hline Isothermal $300^{\circ} \mathrm{C}$ & 56 & 1940 & 571 & - \\
Isothermal $600^{\circ} \mathrm{C}$ & 1 & 15115 & 351 & - \\
TMF no dwell & 18 & 14 & 44 & 10 \\
TMF with dwell & 4 & 363 & 25 & - \\
\hline
\end{tabular}

Predicted lives for models calibrated to isothermal tests show large variations. The Coffin-Manson model severely overestimates the brake disc fatigue life. The Smith-Watson-Topper model either overestimates the fatigue life of the brake disc somewhat $\left(300^{\circ} \mathrm{C}\right)$, or underestimates it $\left(600^{\circ} \mathrm{C}\right)$. The

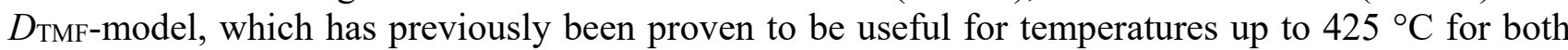
TMF and isothermal cases, substantially overestimates the lives of the brake disc experiment.

\section{Concluding REMARKS}

Reliable computational material models, developed and used for simulating material response to various loading conditions, are needed in fatigue life predictions of, for instance, brake discs. The idea is that experimental testing on full-scale brake disc dynamometers should only be required in a final validation knowing that performing experiments in a laboratory is generally costly and timeconsuming. In the present study, results from isothermal fatigue tests at $300{ }^{\circ} \mathrm{C}$ and $600{ }^{\circ} \mathrm{C}$ and outof-phase thermomechanical fatigue tests between $50{ }^{\circ} \mathrm{C}$ and $700{ }^{\circ} \mathrm{C}$ have been used to calibrate four fatigue life assessment models. It was found that the models calibrated using isothermal tests cannot be adopted for prediction of lives in TMF tests. However, predictions of models calibrated using data from the thermomechanical test without dwell, which originally was designed to mimic the full scale brake experiment, are in reasonable agreement with the estimated crack initiation phase for actual brake disc lives. The analysis of stress-strain hysteresis loops showed that the mechanical properties drop substantially at high temperature (above $500^{\circ} \mathrm{C}$ ). It can be concluded that the mechanisms occurring at elevated temperatures needs further considerations.

\section{ACKNOWLEDGEMENTS}

This work is part of the joint project Improved performance of brake discs between Chalmers and Scania CV AB. It is also part of the project Fatigue of engine materials - TMF and TMF/HCF interactions in cast irons between Linköping University and Scania CV AB. The activities at Chalmers and Linköping University were financed by the government agency VINNOVA in the area Vehicle Development of the FFI Programme (projects 2012-03662 and 2012-03625) and also by the Transport Area of Strength at Chalmers. At Chalmers the project is associated with the activities in the Swedish National Centre of Excellence CHARMEC (CHAlmers Railway MEChanics, see www.chalmers.se/charmec). Professor Roger Lundén of Chalmers is acknowledged for his help, discussions and comments for improving the manuscript, and Dr Peter Skoglund of Scania CV AB for help, fruitful discussions and support. Professor emeritus Bengt Åkesson assisted in improving the manuscript.

\section{REFERENCES}

1. Fan KL, et al. High-temperature low cycle fatigue behavior of a gray cast iron. Materials Characterization 2014; 98: 37-46. 
2. Hornbogen E. Fracture toughness and fatigue crack growth of grey cast irons. Journal of Materials Science 1985; 20(11): 3897-3905.

3. Goettsch D and Dantzig J. Modeling microstructure development in gray cast irons. Metallurgical and Materials Transactions A 1994; 25(5): 1063-1079.

4. Mitchell MR. Effects of graphite morphology, matrix hardness, and structure on the fatigue resistance of gray cast iron. SAE Technical Paper 750198, 1975, 13 pp.

5. Fash JW. Fatigue crack initiation and growth in gray cast iron. Department of Mechanical and Industrial Engineering, FCP Report No 35, College of Engineering, University of Illinois, 1980.

6. Collini L, et al. Influence of casting defects on fatigue crack initiation and fatigue limit of ductile cast iron. Procedia Engineering 2011; 10: 2898-2903.

7. Collini L, et al. Microstructure and mechanical properties of pearlitic gray cast iron. Materials Science and Engineering, part A 2008; 488(1-2): 529-539.

8. Chaboche JL. Time-independent constitutive theories for cyclic plasticity. International Journal of Plasticity 1986; 2(2): 149-188.

9. Chaboche JL. Constitutive equations for cyclic plasticity and cyclic viscoplasticity. International Journal of Plasticity 1989; 5(3): 247-302.

10. Hjelm HE. Yield surface for grey cast iron under biaxial stress. Journal of Engineering Materials and Technology 1994; 116(2): 148-153.

11. Metzger M, et al. On the thermo-mechanical fatigue behavior of the gray cast iron materials GJV-400 and GJL-250: Experiments, modelling and application to GJL-250 cylinder heads. ResearchGate 2015: 21 pp.

12. Milella PP. Fatigue and corrosion in metals: Springer Milan, 2013.

13. Goodman J. Mechanics Applied to Engineering: Longmans, Green and Co., London, 1919.

14. Morrow J. Fatigue properties of metals, Section 3.2. Fatigue Design Handbook. Warrendale, PA: Society of Automotive Engineers, Pub. No. AE-4; 1968.

15. Smith KN, et al. A stress-strain function for the fatigue of metals. Journal of Materials 1970; 5: 767-778.

16. Walker K. The effect of stress ratio during crack propagation and fatigue for 2024-T3 and 7075-T6 aluminum. Effects of environment and complex load history on fatigue life. ASTM International, West Conshohocken, PA: ASTM STP 462; 1970. p. 1-14.

17. Schütz W. Über eine Beziehung zwischen der Lebensdauer bei konstanter und veränderlichen Beanspruchungsamplituden und ihre Anwendbarkeit auf die Bemessung von Flugzeugbauteilen. Zeitschrift für Flugwissenschaften 1967; 15: 407-419.

18. Gerber H. Bestimmung der zulässigen Spannungen in Eisen-Konstructionen. Zeitschrift des Bayerischen Architekten- und Ingenieur-Vereins 1874; 6: 101-110.

19. Söderberg CR. Factor of safety and working stress. Transaction of American Socity of Mechanical Engineering, Part APM-52-2, 1930; 52: 13-28.

20. Wellinger K and Dietmann H. Festigkeitsberechnung - Grundlagen und technische Anwendung. Stuttgart: Alfred Kroener, 1976.

21. Manson SS. Fatigue: A complex subject - Some simple approximations. Experimental Mechanics 1965; 5: 193-226.

22. Coffin LF. A study of the effect of cyclic thermal stresses on a ductile metal. Transaction of American Socity of Mechanical Engineering 1954; 76:931-50.

23. Basquin BO. The exponential law of endurance tests. Proceedings - American Society for Testing Materials 1910; 10: 625-630.

24. Dowling NE, et al. Mean stress effects in stress-life fatigue and the Walker equation. Fatigue and Fracture of Engineering Materials and Structures 2009; 32(3): 163-179.

25. Ince A and Glinka G. A modification of Morrow and Smith-Watson-Topper mean stress correction models. Fatigue and Fracture of Engineering Materials and Structures 2011; 34(11): 854-867. 
26. Burger R and Lee YL. Assessment of the mean-stress sensitivity factor method in stress-life fatigue predictions. Journal of Testing and Evaluation 2013; 41(2).

27. Lee Y-L, et al. Metal fatigue analysis handbook: practical problem-solving techniques for computer-aided engineering. Waltham, MA: Butterworth-Heinemann, 2012.

28. Fash J and Socie DF. Fatigue behaviour and mean effects in grey cast iron. International Journal of Fatigue 1982; 4(3): 137-142.

29. Gocmez $\mathrm{T}$, et al. A new low cycle fatigue criterion for isothermal and out-of-phase thermomechanical loading. International Journal of Fatigue 2010; 32(4): 769-779.

30. Pevec M, et al. Elevated temperature low cycle fatigue of grey cast iron used for automotive brake discs. Engineering Failure Analysis 2014; 42: 221-230.

31. Ekberg A. Fatigue and fracture (course MHA 140). Chalmers University of Technology, Gothenburg, Sweden.

32. Pugno N, et al. A generalized Paris' law for fatigue crack growth. Journal of the Mechanics and Physics of Solids 2006; 54(7): 1333-1349.

33. Suresh S and Ritchie RO. Propagation of short fatigue cracks. International Metal Reviews 1984; 29(6): 445-475.

34. Correia JAFO, et al. Crack closure effects on fatigue crack propagation rates: Application of a proposed theoretical model. Advances in Materials Science and Engineering 2016: 11 pp.

35. Seifert T and Riedel H. Mechanism-based thermomechanical fatigue life prediction of cast iron. Part I: Models. International Journal of Fatigue 2010; 32(8): 1358-1367.

36. Metzger $M$ and Seifert T. A mechanism-based model for LCF/HCF and TMF/HCF life prediction: Multiaxial formulation, finite-element implementation and application to cast iron. Technische Mechanik 2012; 32(2): 435-445.

37. Metzger M, et al. Lifetime prediction of cast iron materials under combined thermomechanical fatigue and high cycle fatigue loading using a mechanism-based model. International Journal of Fatigue 2013; 53: 58-66.

38. Schmitt W, et al. Modelling the fatigue life of automobile components. In: Blom AF (editor), Fatigue 2002 - proceedings of the eighth international fatigue congress held. 3-7 June 2002, Stockholm, Sweden 2002, 781-788 pp.

39. Skoglund P, et al. Fatigue and strength of new grey iron alloys for brake discs. In: 7:th International Conference on Low Cycle Fatigue (LCF-7). Aachen, Germany, September 2013, $6 \mathrm{pp}$.

40. Le Gigan $\mathrm{G}$, et al. Modelling of grey cast iron for application to brake discs for heavy vehicles. Proceedings of the Institution of Mechanical Engineers, Part D: Journal of Automobile Engineering 2017; 231(1): 35-49.

41. Le Gigan G, et al. Disc brakes for heavy vehicles: An experimental study of temperatures and cracks. Proceedings of the Institution of Mechanical Engineers, Part D: Journal of Automobile Engineering 2015; 229(6): 684-707.

42. Hähner $P$, et al. Validated code of practise for thermo-mechanical fatigue testing. Deliverable D12 of European Union Project GRD2-2000-30014, 2006. p. 36.

43. Guillemer-Neel C, et al. Cyclic deformation behaviour and Bauschinger effect in ductile cast iron. Materials Science and Engineering A 1999; 272(2): 431-442.

44. Downing SD. Modeling cyclic deformation and fatigue behavior of cast iron under uniaxial loading. $\mathrm{PhD}$ Thesis, College of Engineering, University of Illinois at Urbana-Champaign, USA, 1984.

45. Pippan R and Grosinger W. Fatigue crack closure: From LCF to small scale yielding. International Journal of Fatigue 2013; 46: 41-48.

46. Ellyin F. Cyclic Strain Energy Density as a Criterion for Multiaxial Fatigue Failure. Brown MW, Miller KJ (editors). London: Mechanical Engineering Publication, 1989.

47. Norman V, et al. Thermo-mechanical and superimposed high-cycle fatigue interactions in compacted graphite iron. International Journal of Fatigue 2015; 80: 381-390. 
48. Socie DF, et al. Fatigue of gray cast iron. College of Engineering, University of Illinois at Urbana-Champaign, Urbana, Illinois, USA, 1982.

49. Weinacht DJ and Socie DF. Fatigue damage accumulation in grey cast iron. International Journal of Fatigue 1987; 9(2): 79-86.

50. Tong X, et al. Thermal fatigue behavior of gray cast iron with striated biomimetic non-smooth surface. Journal of Materials Processing Technology 2008; 206(1-3): 473-480.

51. Norman V, et al. Damage evolution in compacted graphite iron during thermomechanical fatigue testing. International Journal of Cast Metals Research 2016; 29(1-2): 26-33.

52. Suresh S. Fatigue of Materials, 2nd Edition: Cambridge University Press, 1998.

53. Weinacht DJ. Fatigue behavior of gray cast iron under torsional loads. College of Engineering, University of Illinois at Urbana-Champaign, Department of Mechanical and Industrial Engineering / Division of Materials and Design, 1986.

54. DeLa'O JD, et al. Development of a cast iron fatigue properties database for use in modern design methods. Department of Energy, DOE/ID13852, Climax Research Services, Washington DC (USA), 2003.

55. Schweizer C, et al. Mechanisms and modelling of fatigue crack growth under combined low and high cycle fatigue loading. International Journal of Fatigue 2011; 33(2): 194-202.

56. Norman $\mathrm{V}$, et al. The effect of superimposed high-cycle fatigue on thermo-mechanical fatigue in cast iron. International Journal of Fatigue 2016; 88: 121-131.

57. Le Gigan G. Improvement in the brake disc design for heavy vehicles by parametric evaluation. Proceedings of the Institution of Mechanical Engineers, Part D: Journal of Automobile Engineering 2017: 19 pp. 